\title{
Dynamic modification of the capillary wall for electrophoretic separations of small ions
}

\author{
Ming-Mu Hsieh ${ }^{\mathrm{a}}$, Yi-Chun Kuo ${ }^{\mathrm{b}}$, Myan-jen Lyu ${ }^{\mathrm{b}}$, Huan-Tsung Chang ${ }^{\mathrm{a}, *}$ \\ ${ }^{a}$ Department of Chemistry, National Taiwan University, 1 Roosevelt Road, Section 4, P.O. Box 23-34, Taipei 10764, Taiwan \\ ${ }^{\mathrm{b}}$ Department of Agriculture Chemistry, National Taiwan University, Taipei, Taiwan
}

Received 25 April 2000; received in revised form 27 July 2000; accepted 24 August 2000

\begin{abstract}
Separations of small ions were carried out under nonequilibrated conditions using capillaries treated with $\mathrm{NaOH}, \mathrm{HCl}$, or tris(hydroxymethyl)aminomethane (Tris) prior to analysis. For separations of benzoic acid isomers or acids and amines under weakly acidic conditions, capillaries flushed with $0.1 \mathrm{M} \mathrm{NaOH}$ and subsequently with running buffers prior to analysis were used. Separations of six benzoic acid isomers were accomplished in $4 \mathrm{~min}$ in $1 \mathrm{~m} M$ phosphate buffers, $\mathrm{pH} 4.01$, containing $2.5 \mathrm{~m} M$ hydroxypropyl- $\beta$-cyclodextrin. Without additives, the separation of biological amines and acids were also achieved in $10 \mathrm{~min}$ at $\mathrm{pH} 4.01$. Capillaries treated with $0.1 \mathrm{M} \mathrm{HCl}$ prior to analysis were tested in separations of six phenols in $5 \mathrm{mM}$ Tris solutions at $\mathrm{pH}$ 7.0. As a result of small electrophoretic mobilities of phenols against a small electroosmotic flow, resolution was optimized. We also found that reproducibility was improved using capillaries treated with $\mathrm{HCl}$. The relative standard deviations of migration mobility of phenols were less than $1 \%$, which were smaller than those obtained using capillaries treated with $0.1 \mathrm{M} \mathrm{NaOH}$ or Tris. (c) 2000 Elsevier Science B.V. All rights reserved.
\end{abstract}

Keywords: Electroosmotic flow; Buffer composition; Capillary columns; Benzoic acids; Amines; Phenols; Catecholamines

\section{Introduction}

Control of composition and charge of the capillary wall is critical in regulating electroosmotic flow (EOF) in capillary electrophoresis (CE), which in turn affects resolution and speed [1-4]. Although the interaction between analytes and the capillary wall may provide excellent separations under optimal conditions [5], adsorption via electrostatic interaction, hydrogen bonding and hydrophobic patches compromises reproducibility and resolution. There have been several approaches to EOF control.

*Corresponding author. Tel./fax: +886-2-2362-1963.

E-mail address: changht@mail.ch.ntu.edu.tw (H.-T. Chang).
Choosing suitable electrolytes is important because the zeta $(\zeta)$ potential increases with increasing $\mathrm{pH}$ of electrolytes and decreases with increasing ionic strength of electrolytes [6,7]. In order to optimize resolution and minimize variations of the EOF, capillaries coated with polymers have been used for separations of small ions [8-10]. However the coating process is time consuming and/or the capillary has a limited life. For rapid separations of anions under acidic conditions, cationic surfactants such as cetyltrimethylammonium bromide (CTAB) and hexadimethrine bromide (HDB) were used to reverse the EOF $[11,12]$. EOF can also be reversed when dynamic modifiers such as polyamines and polyammonium salts are employed in the back- 
ground electrolyte [13,14]. As a result of high anodic EOF (EOF towards the anode), high-speed separations of acids under acidic conditions have been achieved. However, a high background, irreproducibility, unstable baseline and loss of resolution may be problems.

Although CE with high resolving power has been used in the analysis of small analytes, special techniques such as gradient methods in $\mathrm{CE}$ are needed for analysis of samples with a variety of dissociation constant $\left(K_{\mathrm{a}}\right)$ values. In order to achieve fast speed and high resolving power for separating anions, voltage programming and $\mathrm{pH}$ gradients have been demonstrated $[15,16]$. Resolution can also be optimized by dynamic control of the EOF via application of field amplification and external electric fields $[17,18]$. Although they are superior in some cases, compatibility with most CE commercial instruments is a question. Alternatively, dynamic changes of the EOF and the electrophoretic mobility (EPM) of analytes by buffer electrolysis at high electric field strengths have been demonstrated, in which buffer $\mathrm{pH}$ temporarily increases at the cathode and decreases at the anode [19-21]. The electrolysis rate depends on electric field strength, capillary size and ionic strength of electrolytes.

It is a general rule that resolution can be optimized when the separation is performed at $\mathrm{pH}$ close to the $\mathrm{p} K_{\mathrm{a}}$ values of analytes [22]. However it is not always true if the EOF is too small or too high under such conditions. For example, the cathodic EOF (EOF toward the cathode) is too small in the separation of acids at $\mathrm{pH} 4.0$, and it is too high in the separation of basic analytes above $\mathrm{pH} 7.0$ [23-25]. To optimize resolution and speed, we developed a technique for the separation of organic acids in weakly acidic solutions under nonequilibriated conditions [26-28]. After treating the capillary with $0.1 M \mathrm{NaOH}$, the density of the negative charge in the capillary wall was high, leading to a high EOF at $\mathrm{pH} 4.01$ that was able to move organic acids toward the cathode. As a result of migration of the anions against the high EOF, resolution and speed were optimized. In an attempt to improve reproducibility, optimize resolution, and/or accelerate speed for separating phenols, isomers, or acids and amines under nonequilibriated conditions, capillaries treated with acids or bases were used.

\section{Experimental}

\subsection{Instrumentation}

A commercial electrophoresis instrument from Bio-Rad (BioFocus CE 2000, Hercules, CA, USA) was used. Fused-silica capillaries (Polymicro Technologies, Phoenix, AZ, USA) of $35 \mathrm{~cm} \times 75 \mu \mathrm{m}$ I.D. were used. At $5 \mathrm{~cm}$ from the outlet end, the polyimide coating was burned off to form the detection window. The absorbance of benzoic acid isomers, amines and acids, and phenols were determined at $225 \mathrm{~nm}, 280 \mathrm{~nm}$ and $218 \mathrm{~nm}$, respectively.

\subsection{Materials}

Nitrobenzoic (NBA) and hydroxybenzoic acid (HBA) isomers, $p$-aminobenzoic acid, tryptamine, serotonin creatinine sulfate monohydrate (5-HT), epinephrine (E), L-tryptophan, 5-hydroxyindole-3acetic acid (HIAA), 4-hydroxy-3-methoxybenzoic acid (VA), homovanillic acid (HVA), vanilmandelic acid (VMA), phosphoric acid and sodium dihydrogenphosphate were all of reagent grade and were obtained from Aldrich (Milwaukee, WI, USA). Benzoic acid, Tris and $\mathrm{HCl}$ were of reagent grade and were obtained from Acros (Pittsburgh, PA, USA). Phenol, 2,4-dichlorophenol, 4-nitrophenol and 2,4dinitrophenol were from Merck (Darmstadt, Germany). 2-Nitrophenol and 2,4,6-trichlorophenol were obtained from Tokyo Chemical Industry (Tokyo, Japan). Sodium hydroxide was from Fisher (Fair Lawn, NJ, USA). Buffer solutions were $1 \mathrm{~m} M$ $\mathrm{NaH}_{2} \mathrm{PO}_{4}$ or $5 \mathrm{~m} M$ Tris adjusted with $0.1 \mathrm{M} \mathrm{H}_{3} \mathrm{PO}_{4}$ to different $\mathrm{pH}$. The injected concentration of each analyte is $3 \cdot 10^{-4} M$. Mesityl oxide was used to measure EOF coefficients $\left(\mu_{\text {eof }}\right)$.

\subsection{Capillary equilibrium and separation}

Capillaries were pre-equilibrated with $0.1 \mathrm{M}$ $\mathrm{NaOH}$ overnight prior to their use for electrophoretic separations under acidic conditions. In order to keep a high density of negative charges on the capillary surface, capillaries were only flushed with $0.1 \mathrm{M}$ $\mathrm{NaOH}$ via high pressure (689 $476 \mathrm{~Pa}$ ) for 4 min and subsequently with phosphate buffers for $10 \mathrm{~s}$ between runs. Similarly, capillaries were treated with 
$0.1 M \mathrm{NaOH}, \mathrm{HCl}$ or Tris, respectively, and subsequently with Tris buffers for separations of phenols. Analytes were introduced into the capillaries by applying a high voltage at $10 \mathrm{kV}$ for $3 \mathrm{~s}$.

\section{Results and discussion}

\subsection{Separation of benzoic acid isomers}

The separation of a number of groups of acidic isomers, with a wide range of $K_{\mathrm{a}}$ values, is difficult because some of their $K_{\mathrm{a}}$ values are close. For example, it is impossible to separate the six sample isomers, with $\mathrm{p} K_{\mathrm{a}}$ values ranging from 2.16 to 4.48 , in $10 \mathrm{~m} M$ phosphate buffers, $\mathrm{pH}$ from 4.0 to 7.0, containing cyclodextrins (CDs) under equilibrated conditions (the capillary was equilibrated with the running buffer for $30 \mathrm{~min}$ prior to analysis). This is because either the EOF was too small at $\mathrm{pH}<5.0$ or the acidic isomers dissociated more completely above pH 5.0. Fig. 1 shows that mesityl oxide and the six benzoic acid isomers were separated in $4 \mathrm{~min}$ using $1 \mathrm{~m} M$ phosphate, $\mathrm{pH} 4.0$, containing $2.5 \mathrm{mM}$ hydroxypropyl (HP)- $\beta-\mathrm{CD}$. Compared to the results obtained by isotachophoresis or by regulating the EOF with CTAB or organic solvents [29-34], the separation is much faster as a result of a high EOF $\left[5.87 \cdot 10^{-4} \mathrm{~cm}^{2} \mathrm{~V}^{-1} \mathrm{~s}^{-1}\right.$, relative standard deviation $(\mathrm{RSD})=1.8 \%]$. The high EOF was generated because of a high density of negative charges in the capillary wall and the use of a low concentration of phosphate buffers. It is important to mention that in order to obtain high EOF and reproducibility, it is essential to flush the capillary with $0.1 \mathrm{M} \mathrm{NaOH}$ and subsequently with the running buffer between runs. If EOF decreases $\left(<5.5 \cdot 10^{-4} \mathrm{~cm}^{2} \mathrm{~V}^{-1} \mathrm{~s}^{-1}\right)$ were found, which generally occurred after 30 cycles (about $5 \mathrm{~h}$ ), the capillaries had to be equilibrated in $0.1 \mathrm{M} \mathrm{NaOH}$ at $1 \mathrm{kV}$ for $20 \mathrm{~min}$. A high EOF and good reproducibility ( $\mathrm{RSD}<3 \%$ for 30 cycles) indicates that EOF variations related to continuous modification of the wall surface by buffer components and solutes were not marked.

In this study, resolution was optimized at $\mathrm{pH} 4.01$ for several reasons. First, differential dissociation degrees among anions were comparatively large at $\mathrm{pH} 4.01$ as shown in Table 1. Secondly, the EPM

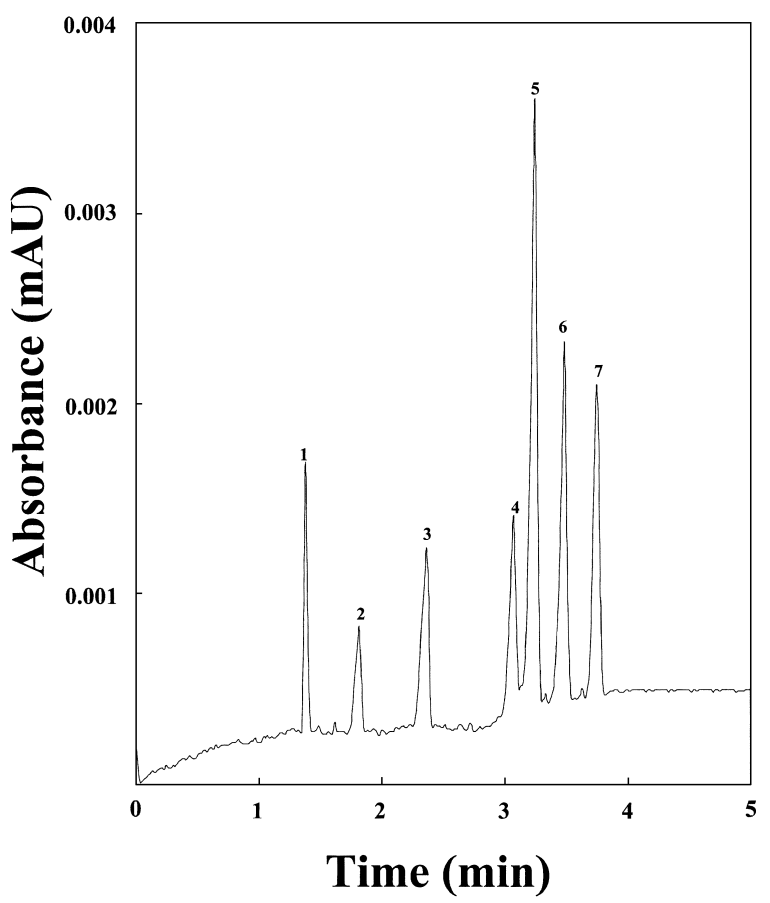

Fig. 1. Separation of mesityl oxide and six benzoic acid isomers in $1 \mathrm{~m} M$ phosphate buffers, $\mathrm{pH} 4.01$, containing $2.5 \mathrm{~m} M$ HP- $\beta$ $\mathrm{CD}$ at $22 \mathrm{kV}$. The capillary was treated with $0.1 \mathrm{M} \mathrm{NaOH}$ for 4 min and subsequently flushed with the running buffer via high pressure for $10 \mathrm{~s}$. Peak identities: $1=$ mesityl oxide; $2=p$-HBA; $3=m-\mathrm{HBA} ; 4=p$-NBA; $5=m-\mathrm{NBA} ; 6=o-\mathrm{HBA} ;$ and $7=o-\mathrm{NBA}$. Capillary: $35 \mathrm{~cm}(30 \mathrm{~cm}$ effective length $) \times 75 \mu \mathrm{m}$ I.D. $\times 365 \mu \mathrm{m}$ O.D. Detection wavelength $=225 \mathrm{~nm}$.

values of acids were altered after forming inclusion complexes. HP- $\beta-C D$ is neutral and relatively large compared to acids, the EPM values of isomeric inclusion complexes were small compared to those of free acids. Although use of buffers containing large amounts of HP- $\beta-\mathrm{CD}$ (more than $5 \mathrm{mM}$ ) allows

Table 1

Dissociation constant and the degree of dissociation of benzoic acid isomers at different $\mathrm{pH}$ values

\begin{tabular}{llllll}
\hline & $\mathrm{p} K_{\mathrm{a}}$ & $\alpha$ & & & \\
\cline { 3 - 6 } & & $\mathrm{pH} \mathrm{3.00}$ & $\mathrm{pH} \mathrm{4.00}$ & $\mathrm{pH} \mathrm{5.00}$ & $\mathrm{pH} \mathrm{6.00}$ \\
\hline$p$-HBA & 4.48 & 0.03 & 0.25 & 0.77 & 0.97 \\
$m$-HBA & 4.06 & 0.08 & 0.47 & 0.90 & 0.99 \\
$m$-NBA & 3.47 & 0.25 & 0.77 & 0.97 & 1.00 \\
$p$-NBA & 3.41 & 0.28 & 0.80 & 0.97 & 1.00 \\
$o$-HBA & 2.97 & 0.52 & 0.91 & 0.99 & 1.00 \\
$o$-NBA & 2.16 & 0.87 & 0.99 & 1.00 & 1.00 \\
\hline
\end{tabular}


rapid separations, the optimal concentration of HP- $\beta$ CD was $2.5 \mathrm{mM}$ at $\mathrm{pH} 4.01$ in terms of speed and resolution. From the magnitude of the decrease in the EPM of acids in the presence of HP- $\beta-C D$, we know the order of the formation constants for isomers and $\mathrm{HP}-\beta$-CD is $p$-HBA $>p$-NBA $>m$-HBA $>m$-NBA $>$ $>o$-HBA $\sim o$-NBA [35]. Thirdly, resolution was optimized by the fact that isomeric anions and isomeric inclusion complexes migrated against the EOF. Finally, dynamic changes of the EOF and $\mathrm{pH}$ due to buffer electrolysis must also be considered. The differential EPM values between any two acids became larger as a result of gradual decrease in EOF and increasing differences in dissociation degrees of acids due to decreases in $\mathrm{pH}$. It should be noted that reproducibility of the separation is quite reasonable (RSD of the migration time of $o-\mathrm{NBA}$ is $2.5 \%$ ), presumably because the capillary surface was refreshed after each run.

\subsection{Separation of amines and acids}

The determination of catecholamines (CAs) and their metabolites is considerable because they are neurotransmitters in the central and peripheral nervous systems [36]. Fig. 2 shows eight amines and acids were separated in $1.0 \mathrm{~m} M$ phosphate buffers at $\mathrm{pH}$ values, ranging from 2.5 to 4.0 , using the capillary pretreated with $0.1 M \mathrm{NaOH}$ prior to analysis. Because the EPM values of amines (toward the cathode) increased, while those of acids (toward the anode) decreased with decreasing $\mathrm{pH}$, the separations either at low or high $\mathrm{pH}$ were not suitable. At low $\mathrm{pH}(<3.0)$, irreproducibility and longer separation times were problems. These are most likely due to adsorption of neutral acids and marked decrease in EOF. On the other hand, the separation at $\mathrm{pH}$ higher than 4.5 was not suitable because amines tend to adsorb onto the capillary wall and differential EPM values between amines were small. This proposed method provided advantages over micellar electrokinetic chromatography (MEKC) under basic conditions [37,38], including stability of amines and reduced adsorption. In addition, without adding detergents, the method should be more suitable for simultaneous analysis of low concentrations of amines and acids in biological samples by laserinduced fluorescence (LIF) with a UV laser [39]. We
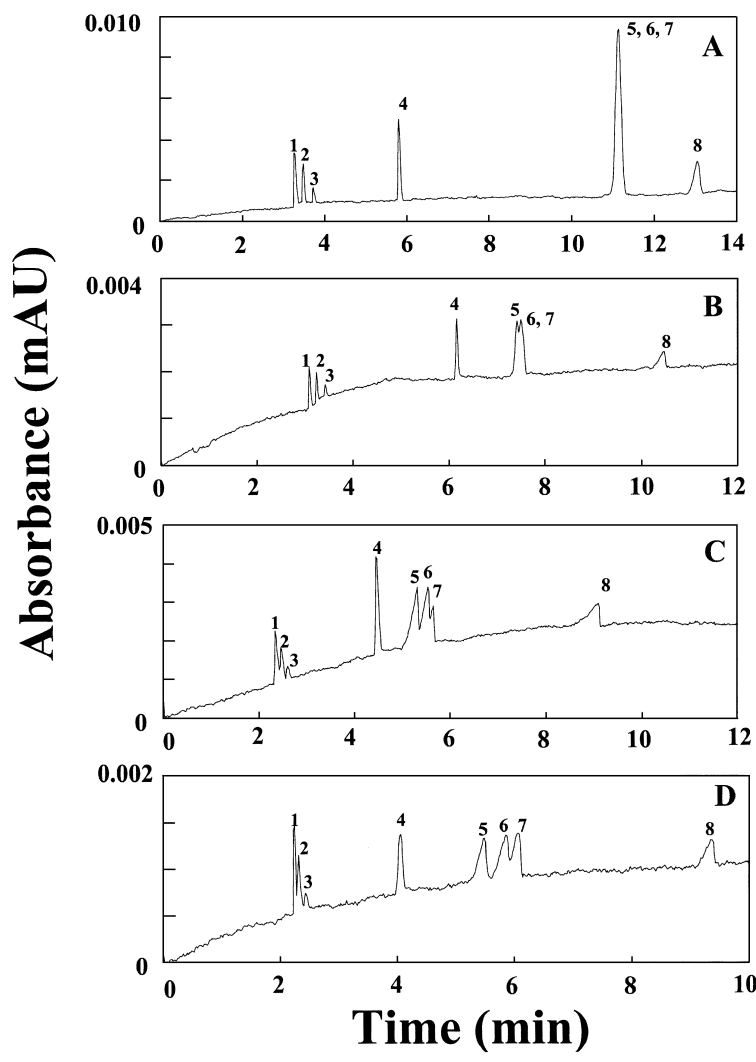

Fig. 2. Separations of biological amines and acids in $1 \mathrm{~m} M$ phosphate buffers in $\mathrm{CE}$ at $10 \mathrm{kV}$. (A) $\mathrm{pH} 2.50$; (B) $\mathrm{pH} 3.00$; (C) $\mathrm{pH} 3.50$; and (D) $\mathrm{pH} 4.00$. The capillary was treated with $0.1 \mathrm{M}$ $\mathrm{NaOH}$ for 4 min and subsequently flushed with the running buffer via high pressure for $10 \mathrm{~s}$. Capillary: $36 \mathrm{~cm}(31 \mathrm{~cm}$ effective length $) \times 75 \mu \mathrm{m}$ I.D. $\times 365 \mu \mathrm{m}$ O.D. Detection wavelength was set at $280 \mathrm{~nm}$. Peak identities: $1=$ tryptamine; $2=5-\mathrm{HT} ; 3=\mathrm{E}, 4={ }_{\mathrm{L}}-$ tryptophan; $5=5$-HIAA; $6=\mathrm{VA} ; 7=\mathrm{HVA}$; and $8=\mathrm{VMA}$.

have found that sodium dodecyl sulfate (SDS) caused fluorescent background using a UV laser at $266 \mathrm{~nm}$, leading to low sensitivity (unpublished results). Thus at low $\mathrm{pH}$ the detection of amines, with high quantum yields, by LIF at $266 \mathrm{~nm}$ should be more sensitive.

\subsection{Separation of phenols}

The separation of phenols, with a wide range of $\mathrm{p} K_{\mathrm{a}}$ values, 4.08 to 10.09 , was not possible by the above method. The separation was also not suitable under alkaline solutions without additives such as SDS under equilibrated conditions, because of high 
EOF. Although adding organic solvent such as ethanol and dimethyl sulfoxide is effective for decreased EOF, changes in the dissociation constant of analytes, leading to changes in resolution, must be considered [40-42]. Fig. 3 shows the separation of six phenols in $5 \mathrm{~m} M$ Tris buffers, $\mathrm{pH} 7.0$, using capillaries treated with $0.1 \mathrm{M} \mathrm{NaOH}$, Tris and $\mathrm{HCl}$ prior to analysis, respectively. The EOF mobilities calculated from the migration times of phenol $\left(\mathrm{p} K_{\mathrm{a}}\right.$ 10.09) were $7.85,6.70$ and $4.41 \cdot 10^{-4} \mathrm{~cm}^{2} \mathrm{~V}^{-1} \mathrm{~s}^{-1}$ using the capillary pretreated with $0.1 \mathrm{M} \mathrm{NaOH}$, Tris and $\mathrm{HCl}$, respectively. The fact that EOF mobility was small using the capillary treated with $\mathrm{HCl}$ indicated that the $\zeta$ potential in the capillary wall was suppressed by partial protonation of the silanol

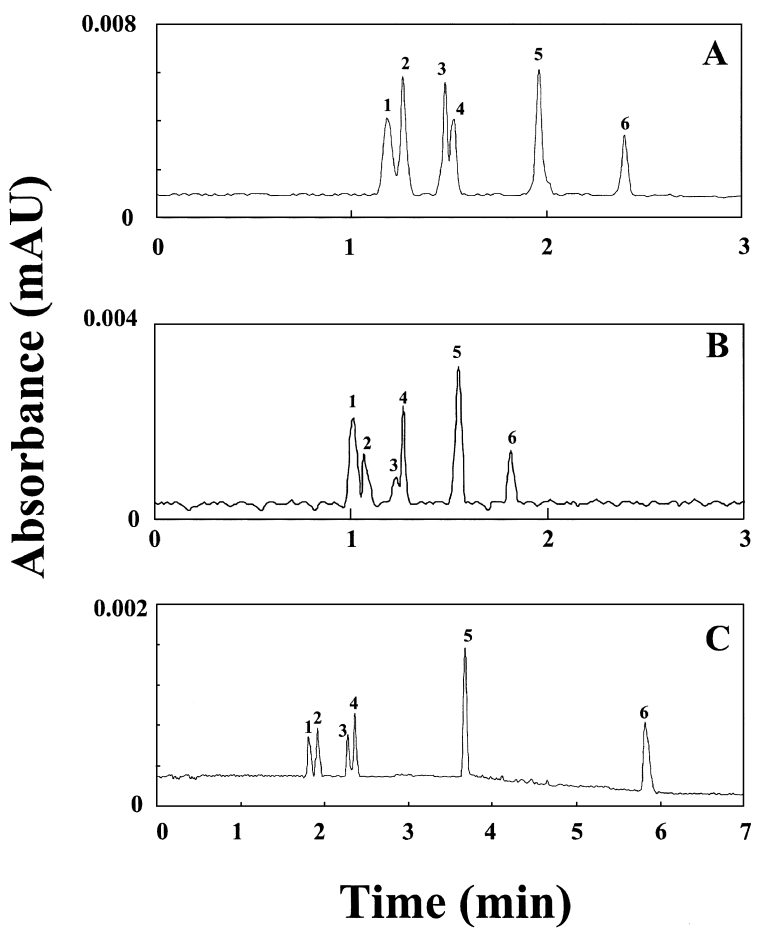

Fig. 3. Separations of six phenols in $5 \mathrm{~m} M$ Tris buffer solution, $\mathrm{pH} 7.0$ at $20 \mathrm{kV}$ using capillaries treated with $0.1 \mathrm{M} \mathrm{NaOH}$, Tris and $\mathrm{HCl}$, respectively, prior to analysis. The capillaries were treated with $0.1 M \mathrm{NaOH}$ (A), Tris (B), and $\mathrm{HCl}(\mathrm{C})$, respectively, for $4 \mathrm{~min}$, and subsequently flushed with $5 \mathrm{mM}$ Tris buffers via high pressure for $10 \mathrm{~s}$. Column: $35 \mathrm{~cm}(30 \mathrm{~cm}$ effective length $) \times$ $75 \mu \mathrm{m}$ I.D. $\times 365 \mu \mathrm{m}$ O.D. Detection wavelength $=218 \mathrm{~nm}$. Peak identities: 1=phenol; 2=2,4-dichlorophenol; 3=2-nitrophenol; 4=4-nitrophenol; 5=2,4,6-trichlorophenol; and 6=2,4-dinitrophenol.
Table 2

Decreases in $\mathrm{pH}$ of the buffers in the anodic vials after separations using capillaries treated with $0.1 \mathrm{M} \mathrm{NaOH}$, Tris or $\mathrm{HCl}$ at $20 \mathrm{kV}$ for $10 \mathrm{~min}$

\begin{tabular}{llll}
\hline Treatment & \multicolumn{2}{l}{$\Delta \mathrm{pH}(\mathrm{SD})^{\mathrm{a}}$} & \\
\cline { 2 - 4 } & $\mathrm{pH} 8.5$ & $\mathrm{pH} 7.0$ & $\mathrm{pH} \mathrm{6.0}$ \\
\hline $\mathrm{NaOH}$ & $-0.05(0.01)$ & $-0.07(0.01)$ & $-1.31(0.05)$ \\
Tris & $-0.05(0.01)$ & $-0.17(0.03)$ & $-1.43(0.08)$ \\
$\mathrm{HCl}$ & $-0.05(0.02)$ & $-0.23(0.04)$ & $-1.69(0.11)$ \\
\hline
\end{tabular}

${ }^{\mathrm{a}}$ Standard deviation $(n=5)$.

groups. In addition, small EOF was likely due to adsorption of Tris cations. It is believed that amines are bound to the wall via ion pair formation with anionic silanol groups or via other interactions such as van der Waals forces [43]. At $\mathrm{pH}$ 7.0, a greater fraction of phosphate exists in the $\mathrm{H}_{2} \mathrm{PO}_{4}^{-}$and $\mathrm{HPO}_{4}^{2-}$ forms, which, being highly charged, would not condense like Tris cations onto the negative surface. Thus, phosphate buffers were not used for a small EOF. Because basic phenols, such as phenol, 2,4-dichlorophenol, 2-nitrophenol and 4-nitrophenol, are not fully dissociated (small EPM) at $\mathrm{pH} 7.0$, a small EOF was generally needed for optimum resolution. For example, resolution values between 2nitrophenol and 4-nitrophenol using the capillary treated with $\mathrm{NaOH}$, Tris, and $\mathrm{HCl}$ were $0.7,0.8$, and 1.2 , respectively. Since the capillary was dynamically modified with buffer compositions and the $\mathrm{pH}$ decreased at the anode end due to buffer electrolysis, the differential migration times between any two phenolic compounds became larger at low $\mathrm{pH}$. Table 2 shows the $\mathrm{pH}$ of the buffers in the anodic vials decreased in the following order: $\mathrm{pH} 6.0>\mathrm{pH} 7.0>$ $\mathrm{pH} 8.5$, which agreed with the buffer capacity of Tris $\left(\mathrm{p} K_{\mathrm{a}}=8.08\right)$. Table 3 shows that reproducibility of the migration mobility (directly calculated from migration time) of five phenols at $\mathrm{pH} 7.0$ was good $(\mathrm{RSD}<2.5 \%)$. Of interest to note that the use of capillaries pretreated with $\mathrm{HCl}$ provided better reproducibility $(\mathrm{RSD}<1 \%)$.

\section{Conclusions}

Regulation of adsorption of molecules on the capillary wall, leading to the possibility of controlling the EOF, is important with respect to speed, 
Table 3

Reproducible migration mobilities $\left(\mu ; 10^{-4} \mathrm{~cm}^{2} \mathrm{~V}^{-1} \mathrm{~s}^{-1}\right)$ of six phenols using capillaries treated with $\mathrm{NaOH}, \mathrm{THAM}$ or $\mathrm{HCl}$ at $\mathrm{pH} 7.0$

\begin{tabular}{|c|c|c|c|c|c|c|c|c|c|c|c|c|c|c|c|}
\hline \multirow[t]{3}{*}{ Analyte $^{a}$} & \multicolumn{15}{|l|}{$\mu$} \\
\hline & \multicolumn{5}{|c|}{$\mathrm{NaOH}$} & \multicolumn{5}{|c|}{ THAM } & \multicolumn{5}{|l|}{$\mathrm{HCl}$} \\
\hline & 1 & 2 & 3 & Mean & $\begin{array}{l}\text { RSD } \\
(\%)\end{array}$ & 1 & 2 & 3 & Mean & $\begin{array}{l}\text { RSD } \\
(\%)\end{array}$ & 1 & 2 & 3 & Mean & $\begin{array}{l}\text { RSD } \\
(\%)\end{array}$ \\
\hline 1 & 7.65 & 7.95 & 7.95 & 7.85 & 0.25 & 6.63 & 6.68 & 6.80 & 6.70 & 1.30 & 4.42 & 4.39 & 4.42 & 4.41 & 0.39 \\
\hline 2 & 7.30 & 7.43 & 7.50 & 7.41 & 1.10 & 6.21 & 6.26 & 6.36 & 6.28 & 1.22 & 4.12 & 4.14 & 4.14 & 4.14 & 0.28 \\
\hline 3 & 6.36 & 6.47 & 6.47 & 6.43 & 1.00 & 5.30 & 5.37 & 5.40 & 5.39 & 0.92 & 3.49 & 3.49 & 3.49 & 3.49 & 0.00 \\
\hline 4 & 6.26 & 6.31 & 6.31 & 6.30 & 0.46 & 5.17 & 5.23 & 5.30 & 5.23 & 1.24 & 3.36 & 3.37 & 3.36 & 3.36 & 0.17 \\
\hline 5 & 5.10 & 5.13 & 5.17 & 5.13 & 0.68 & 3.98 & 4.06 & 4.14 & 4.06 & 1.97 & 2.16 & 2.15 & 2.16 & 2.16 & 0.27 \\
\hline 6 & 4.37 & 4.37 & 4.39 & 4.38 & 0.26 & 3.25 & 3.33 & 3.40 & 3.32 & 2.26 & 1.38 & 1.36 & 1.37 & 1.37 & 0.73 \\
\hline
\end{tabular}

${ }^{\mathrm{a}} 1=$ Phenol $\left(\mathrm{p} K_{\mathrm{a}}=10.09\right) ; 2=2,4$-dicholophenol $\left(\mathrm{p} K_{\mathrm{a}}=8.51\right) ; 3=2$-nitrophenol $\left(\mathrm{p} K_{\mathrm{a}}=7.22\right) ; 4$ 4-nitrophenol $\left(\mathrm{p} K_{\mathrm{a}}=7.15\right) ; 5=2,4,6$ trichlorophenol $\left(\mathrm{p} K_{\mathrm{a}}=6.51\right)$; and $6=2,4$-dinitrophenol $\left(\mathrm{p} K_{\mathrm{a}}=4.08\right)$.

resolution, and accuracy in $\mathrm{CE}$. The method of achieving a high anodic EOF at low $\mathrm{pH}$ allows for rapid separations of two groups of isomers, with a $\mathrm{p} K_{\mathrm{a}}$ range from 2.16 to 4.48 . These isomers were not completely separated in phosphate buffers containing CDs in the presence of CTAB (high cathodic EOF) over a $\mathrm{pH}$ range from 2.0 to 4.5 . A better resolution obtained by our proposed method is because acidic isomers migrate against EOF. Without additives, amines and acids were separated in phosphate buffers under weakly acidic conditions. The result indicates that this simple, low costly, low background and rapid method should be useful for analysis of samples containing cations and anions. More importantly, this method shows the potential for trace analysis of amines and their metabolites in cells by LIF using a UV laser. At low $\mathrm{pH}$, the quantum yields of amines are high, leading to lower limits of detection. The separation of phenols using the capillary dynamically modified with acids provides advantages over MEKC [44,45], including simplicity, less background noise, reproducibility, and compatibility with mass spectrometers.

\section{Acknowledgements}

This work was supported by a grant (NSC892113-M-002-062) from the National Science Council of Taiwan.

\section{References}

[1] A. Cifuentes, P. Canalejas, A. Ortega, J.C. Díez-Masa, J. Chromatogr. A 823 (1998) 561.

[2] J. Li, J.S. Fritz, J. Chromatogr. A 840 (1999) 269.

[3] T.W. Graul, J.B. Schlenoff, Anal. Chem. 71 (1999) 4007.

[4] S. Pedersen-Bjergaard, O. Næss, S. Moestue, K.E. Rasmussen, J. Chromatogr. A 876 (2000) 201.

[5] M.M. Bushey, J.W. Jorgenson, J. Chromatogr. 480 (1989) 301.

[6] R.H.P. Reid, J. Chromatogr. A 669 (1994) 151.

[7] N. Cohen, E. Grushka, J. Chromatogr. A 678 (1994) 167.

[8] M. Chiari, L. Ceriotti, G. Crini, M. Morcellet, J. Chromatogr. A 836 (1999) 81.

[9] M. Ye, H. Zou, Z. Liu, J. Ni, J. Chromatogr. A 887 (2000) 223.

[10] D. Belder, K. Elke, H. Husmann, J. Chromatogr. A 868 (2000) 63.

[11] T. Kaneta, S. Tanka, H. Yoshida, J. Chromatogr. 538 (1991) 385.

[12] D. Volgger, A.J. Zemann, G.K. Bonn, M.J. Antal, J. Chromatogr. A 758 (1997) 263.

[13] N. Cohen, E. Grushka, J. Cap. Electrophoresis 2 (1994) 112.

[14] R.S. Madabhushi, Electrophoresis 19 (1998) 224.

[15] J. Sudor, J. Pospichal, M. Deml, P. Bocek, J. Chromatogr. A 545 (1991) 331.

[16] H.-T. Chang, E.S. Yeung, J. Chromatogr. A 632 (1993) 149

[17] R.L. Chien, D.S. Burgi, Anal. Chem. 64 (1992) 489A.

[18] C.S. Lee, D. McManigill, C.T. Wu, Anal. Chem. 63 (1991) 1519.

[19] M.S. Bello, J. Chromatogr. A 744 (1996) 81.

[20] T. Zhu, Y.-L. Sun, C.-X. Zhang, D.-K. Ling, Z.-P. Sun, J. High Resolut. Chromatogr. 17 (1994) 563.

[21] M. Macka, P. Andersson, P.R. Haddad, Anal. Chem. 70 (1998) 743.

[22] F. Foret, P. Boček, Adv. Electrophoresis 3 (1989) 273.

[23] A. Zemann, D. Volgger, Anal. Chem. 69 (1997) 3243. 
[24] M. Chiari, N. Dell'Orto, L. Casella, J. Chromatogr. A 745 (1996) 93.

[25] C.W. Klampfl, W. Buchberger, Trends Anal. Chem. 16 (1997) 221.

[26] M.-M. Hsieh, H.-T. Chang, J. Chromatogr. A 793 (1998) 145.

[27] H.-T. Chang, H.-S. Chen, R. Lee, J. Chromatogr. A 800 (1998) 339.

[28] M.-M. Hsieh, H.-T. Chang, J. Chromatogr. A 817 (1998) 129.

[29] J. Snopek, I. Jelínek, E. Smolkova-Keulemansova, J. Chromatogr. 411 (1987) 153.

[30] S. Fanali, M. Sinibaldi, J. Chromatogr. 442 (1988) 371.

[31] P.D. Ferguson, D.M. Goodall, J.S. Loran, J. Chromatogr. A 768 (1997) 29.

[32] S. Fujiwara, S. Honda, Anal. Chem. 59 (1987) 487.

[33] M.Y. Khaled, H.M. McNair, J. High Resolut. Chromatogr. 19 (1996) 143.

[34] J. Tjørnelund, A. Bazzanella, H. Lochmann, K. Bächmann, J. Chromatogr. A 811 (1998) 211.

[35] Y.Y. Rawjee, D.U. Staerk, G. Vigh, J. Chromatogr. A 635 (1993) 291.
[36] Á. Kovács, L. Simon-Sarkadi, K. Ganzler, J. Chromatogr. A 836 (1999) 305.

[37] R.A. Wallingford, A.G. Ewing, J. Chromatogr. 441 (1988) 299.

[38] D.M. Paquette, R. Sing, P.R. Bank, K.C. Waldron, J. Chromatogr. B 714 (1998) 47.

[39] H.-T. Chang, E.S. Yeung, Anal. Chem. 67 (1995) 1079.

[40] C. Schwer, E. Kenndler, Anal. Chem. 63 (1991) 1801.

[41] S. Morales, R. Cela, J. Chromatogr. A 846 (1999) 401.

[42] M. Rosés, F. Rived, E. Bosch, J. Chromatogr. A 867 (2000) 45.

[43] B. Verzola, C. Gelfi, P.G. Righetti, J. Chromatogr. A 874 (2000) 293.

[44] K. Otsuka, S. Terabe, T. Ando, J. Chromatogr. 348 (1985) 39.

[45] M.A. Rodríguez-Delgado, M.L. Pérez, R. Corbella, G. González, F.J. García Montelongo, J. Chromatogr. A 871 (2000) 427. 